\title{
An examination of relationships between the pleasantness, intensity, and concentration of 10 odorous stimuli
}

\author{
RICHARD L. DOTY \\ Monell Chemical Senses Center, University of Pennsylvania, Philadelphia, Pennsylvania 19104
}

\begin{abstract}
Relationships between physical concentration, perceived pleasantness, and perceived intensity were established by the method of magnitude estimation for 10 diverse chemical stimuli. Estimates of pleasantness significantly correlated with those of intensity for seven of the compounds examined. In all cases, the relationships between perceived intensity and physical concentration were described relatively well by power functions. However, this was not true for the pleasantness/concentration relationships. Intensity exponents correlated moderately with a number of common physicochemical parameters. Large differences were present between individual observer's ratings of the perceived pleasantness of the odorants. These data indicate that the perceived pleasantness of some odorants may be systematically related to their perceived intensity, but do not support the notion that these dimensions are equivalent.
\end{abstract}

A number of experiments suggest that the perceived intensity of olfactory stimuli grows as a power function of their physical concentration (e.g. . Berglund, Berglund. Ekman, \& Engen, 1971; Cain, 1969; Engen \& Lindström, 1963; Jones, 1958; Moskowitz, Dravnieks, \& Gerbers, 1974; Reese \& Stevens, 1960; Engen, Note 1). This relationship is usually expressed by the simple function, $P=k \varnothing^{n}$ (or $\log \mathrm{P}=\mathrm{n} \log \varnothing+\log \mathrm{k}$ ), where $\mathrm{P}=$ perceived intensity, $\mathrm{k}=\mathrm{a}$ constant, $\varnothing=$ stimulus concentration, and $\mathrm{n}=$ the exponent indicating the rate and form of the change in perceived intensity across a series of concentrations. Since intensity exponents for olfactory stimuli presented in liquid diluents are usually less than one, intensity grows as a decelerating function of physical concentration.

Although the perceived pleasantness of odors has been assumed to vary with physical concentration (e.g., Moncrieff, 1966), few studies have systematically examined this assumption and none have tested more than one odorant. Henion (1971) and Moskowitz et al. (1974) have found this assumption to be valid for amyl acetate and n-butanol, respectively. Although Henion (1971) suggested, on the basis of one odorant, that odorant pleasantness and intensity are the same psychological dimension, the data of Moskowitz et al. (1974) did not strongly support this notion.

This study was supported, in part, by Grant RF 72018 from the Rockefeller Foundation. The author thanks L. Alazraki, L. Benson, K. Byrne, M. Ford. S. Freeman, V. Kolaga, H. Moskowitz. M. Orndoff, G. Preti, and T. Seerveld for assistance during this study. Reprint requests should be sent to the author at the Monell Chemical Senses Center. University of Pennsylvania, 3500 Market Street, Philadelphia, Pennsylvania 19104.
The purpose of the present study was to systematically investigate the form of the relationship between physical concentration and perceived intensity and pleasantness for a number of chemically and perceptually diverse stimuli. In addition, exponents of power functions fitted to the intensity estimates were tested for correlation with several common physicochemical indices. Cain (1969) noted, in a homologous series of alcohols, that water solubility correlated positively with the power function of intensity. Doty (1975) presents data which suggest that the power function exponent of intensity may correlate positively with trigeminal stimulative properties of odorants, and that physicochemical indices such as water solubility and molecular weight may be useful in the prediction of such stimulation.

\section{METHOD}

\section{Observers}

The majority of the observers were college students recruited from the Philadelphia vicinity and paid for their participation. The number of observers per odorant condition varied. with the minimum being 17 and the maximum 39. Approximately half were male and half female, and many served as observers for several of the odorant conditions. The mean age of all observers was 24.6 years $(S D=7.1)$.

\footnotetext{
Odorants

The 10 odorants used in this study were of the highest chemical grade available commercially (Suppliers: Fisher Scientitic Company and Eastman Kodak Company) and were purity checked at the Monell Center by gas chromatography before their use as stimuli. They were selected from a group of selected odorants originally chosen by Berglund et al. (1971) to fulfill a number of specitic criteria: (a) none should exceed the moderate rating in Sax's (1966) system of toxic hazards regarding inhalation; (b) there should be a large variation in molecular weight and vapor pressure, as well as in chemical structure; (c) the compounds should have different solubility characteristics in polar and nonpolar solvents; (d) they
} 
should differ qualitatively in odor; and (e) both pleasant and unpleasant odors should be represented.

\section{Procedure}

Quarter-log step dilution series extending from -1 to $-4 \log$ volume concentrations were prepared for each odorant by appropriately proportioning $25 \mathrm{ml}$ of odorant + diluent (propylene glycol) into $100-\mathrm{ml}$ glass jars. A control jar containing $25 \mathrm{ml}$ of the diluent only was also prepared. These "sniff bottles" were covered on the outside by aluminum foil and were capped with Teflon-lined plastic tops between test trials. Odorant sets were prepared fresh daily.

Testing took place at a table located in an air-conditioned room having relatively rapid air turnover. During a trial, the experimenter opened a bottle and held it beneath an observer's nose for approximately $5 \mathrm{sec}$. The observer used any convenient sniffing strategy during this time, and was asked to sniff in the same fashion from trial to trial. The test concentrations for a given odorant were presented in random order, and each observer made only one estimate for each concentration. Only one dimension (e.g., intensity of one odorant) was rated in a given test session, and at least $15 \mathrm{~min}$ were interspersed between test sessions. A $25-\mathrm{sec}$ intertrial interval was enforced within a test session, and the presentation order of the intensity and pleasantness test sessions was randomized. No more than two odorant series were tested on a single day. Before the formal trials, the observers were given a practice trial using three stimuli-one from the top, one from the middle, and one from the bottom third of the concentration series of the odorant under consideration. No feedback was given during these practice trials, which were designed to accustom the observer to the general stimulus range to be presented.

For the intensity estimates, the observer could assign any range of numbers to the stimuli that was convenient. so long as the numbers were in proportion to the perceived intensity of the stimuli. No prescribed modulus was designated. For the pleasantness estimates, a slightly moditied strategy prevailed. If an odorant was neither pleasant nor unpleasant, it was assigned a zero. If it was pleasant. it was assigned a positive number in proportion to its pleasantness. If it was unpleasant, it was assigned a negative number in proportion to its unpleasantness. Such a procedure is a moditication of procedures commonly used in judging affective stimulus attributes and provides a convenient anchor point which separates the pleasant from the unpleasant stimuli (Torgerson, 1958).

\section{RESULTS}

The pleasantness and intensity estimates of five observers who chose extremely large moduli were initially divided by individual factors which brought their magnitude into the general range of values used by others for the odorant under consideration. This preliminary normalization minimized the distorting influence of extreme values upon subsequent normalization procedures and had no influence upon the ratio relationships between the estimates. Arithmetic means and medians were then computed for each concentration of each odorant. The intensity estimates were then further normalized by multiplying each observer's estimates of each odorant concentration series by a factor that made their arithmetic mean equal to the grand mean of the observer/concentration matrix for that odorant. Geometric means were then computed. This normalization procedure and the calculation of geometric means could not be applied to the pleasantness estimates because some observers used both positive and negative numbers and each defined his own zero point which represented "neutrality" rather than an "absence" (logarithms of negative numbers and zero are undefined; the addition of a constant to eliminate the negative values, followed by a normalization procedure and subtraction of the constant or other factor, distorts the initial ratio relationships).

The arithmetic means of the pleasantness and intensity estimates are plotted against log volume concentration in Figure 1. Pearson product moment correlations between the intensity and pleasantness estimates, along with the sample sizes, are also presented in this figure. It is apparent that (a) pleasantness and intensity are closely related for seven of the odorants, (b) total change in pleasantness across the concentration gradients is usually less than total change in intensity, and (c) the relationship of pleasantness and intensity to one another, as well as to odorant concentration, varies markedly from one compound to another.

To establish how well power functions fitted the relationships of perceived intensity and pleasantness to physical concentration, least squares regression lines were computed between the logarithms of the magnitude estimates and stimulus concentrations. The stimulus concentrations were expressed as both (a) mole fractions and (b) volume concentration. Only data points falling at and above the lowest concentration receiving magnitude estimates larger than those of the control diluent were used (t tests, $p<.05)$. The pleasantness ratings of the few compounds having negative values in uniform sequence were made positive to allow logarithmic conversion, and the negative signs were subsequently inserted in front of the exponents (i.e., slopes of the regression lines). In a few cases, the range of stimuli to which the power functions were fitted was limited by the presence of discrepantly signed values at one end of the concentration continuum.

Over the concentrations used in this study, the values of the exponents based on (a) volume concentration and (b) mole fractions were essentially equivalent. Thus, in keeping with the units of Figure 1, the data are expressed only as a function of volume concentration. The concentrations over which the fits were made, along with the determined exponents and $r^{2}$ values, are presented in Table 1 . It is apparent that power functions fitted the intensity data quite well, as indicated by the large $r^{2}$ values. However, this was not true for the pleasantness data. The exponents for the intensity estimates had a relatively small range $(0.21$ to 0.39$)$ compared to those of the pleasantness estimates (absolute values: 0.01 to 1.04).

Despite the smooth and frequently monotonic mean pleasantness curves of Figure 1, there were marked 

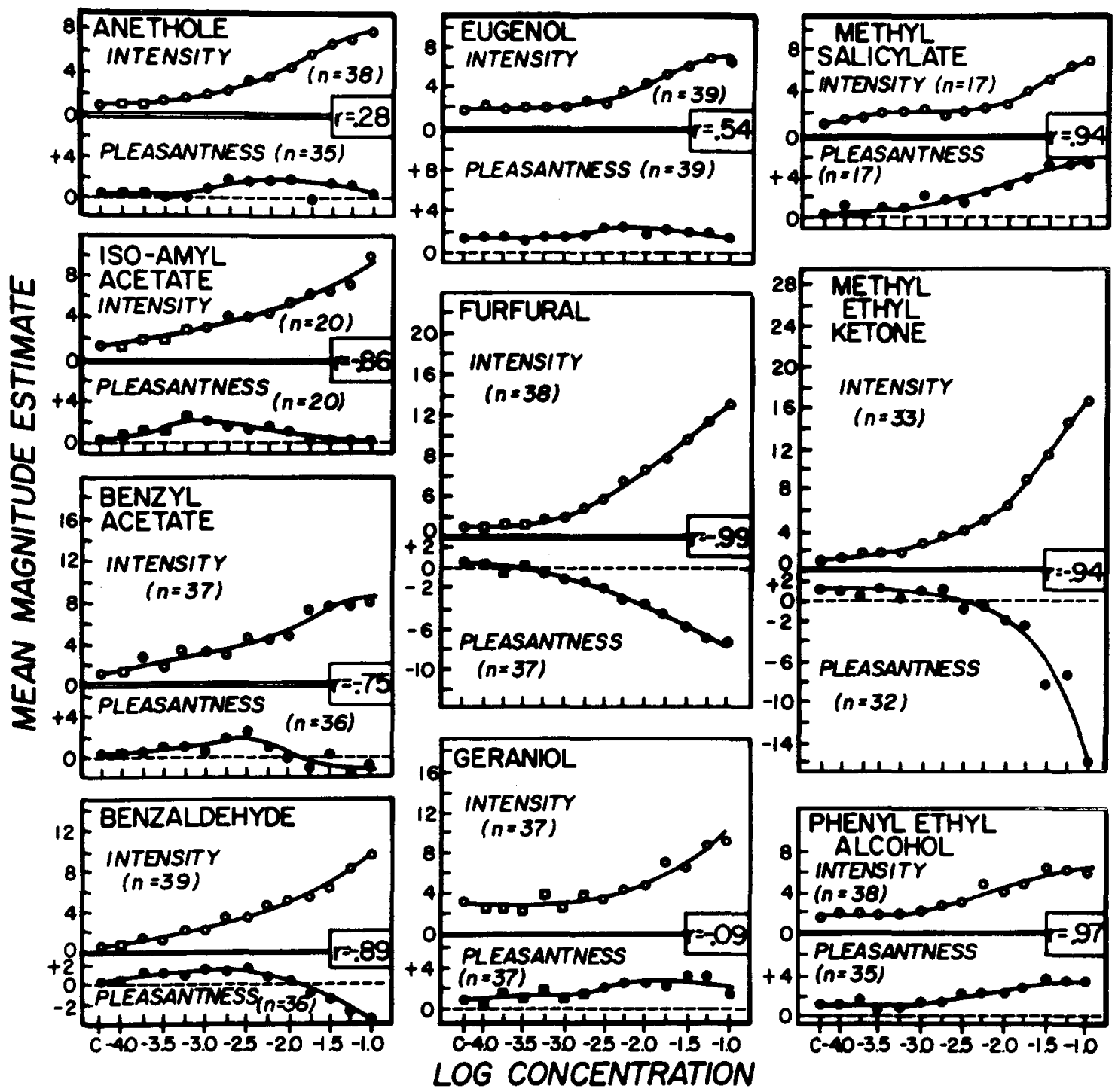

Figure 1. Relationship of mean pleasantness and intensity magnitude estimates to log volume concentration in propylene glycol diluent for 10 compounds. Squares indicate data points not differing significantly in intensity from diluent control, $\mathrm{C}(\mathrm{t}$ tests, $\mathrm{p}<.05$ ). $\mathrm{r}=$ Pearson product moment correlation between pleasantness and intensity estimates across data points differing significantly in intensity from control. All correlations significant beyond the $p<.01$ level except those for anethole $(p>.20)$, eugenol ( $p<.06$ ), and geraniol (p $>$.20). Lines fitted to data points by visual inspection.

differences between observers in their reports of pleasantness for the various compounds. The percent of observers assigning the majority of the stimulus concentrations of each odorant pleasant $(+)$, unpleasant (-), or neutral (0) values illustrates this fact (Table 2). As in the case with fitting power functions, only those estimates at and above the lowest concentration of each substance which received larger magnitude estimates than the control substance were used for analysis (Table 1). In most cases, the same odorant was perceived by some individuals as unpleasant and by others as pleasant. The frequency of individuals using,+- , or 0 categories was not distributed equally among these categories for most of the compounds, as indicated by significant chi-square values (Table 2 ).

Pearson product moment correlations were computed between the intensity power function exponents based upon the geometric means and a number of common physicochemical parameters. The relationships between the intensity exponents and these parameters were as follows: molecular weight, $-0.55, \mathrm{p}<.05$; water solubility $\left(\mathrm{g} / \mathrm{ml} \mathrm{H}_{2} \mathrm{O}\right.$ ca. $\left.20^{\circ} \mathrm{C}\right)$, $0.54, \mathrm{p}<.05$; Carbowax $20 \mathrm{M}$ retention time, -0.44 , 
Table 1

Exponents (n) and Goodness of Fit $\left(r^{2}\right)$ Parameters of Power Functions Fitted to the Pleasantness and Intensity Data

\begin{tabular}{|c|c|c|c|c|c|c|c|c|}
\hline \multirow[b]{2}{*}{ Odorant } & \multirow[b]{2}{*}{ Dimension } & \multirow{2}{*}{$\begin{array}{c}\text { Concentration } \\
\text { Range* }^{*}\end{array}$} & \multicolumn{2}{|c|}{$\begin{array}{c}\text { Geometric } \\
\text { Means }\end{array}$} & \multicolumn{2}{|c|}{$\begin{array}{c}\text { Arithmetic } \\
\text { Means } \\
\end{array}$} & \multicolumn{2}{|c|}{ Medians } \\
\hline & & & $\mathbf{n}$ & $\mathbf{r}^{2}$ & $\mathrm{n}$ & $\mathrm{r}^{2}$ & $\mathrm{n}$ & $r^{2}$ \\
\hline $\begin{array}{l}\text { iso-Amyl } \\
\text { Acetate }\end{array}$ & $\begin{array}{l}\text { Intensity } \\
\text { Pleasantness }\end{array}$ & $\begin{array}{l}-3.00 \text { to }-1.00 \\
-3.00 \text { to }-1.00\end{array}$ & .23 & .96 & $\begin{array}{r}.23 \\
-1.04\end{array}$ & $\begin{array}{l}.93 \\
.71\end{array}$ & $\begin{array}{r}.25 \\
-.08\end{array}$ & $\begin{array}{l}.79 \\
.13\end{array}$ \\
\hline Anethole & $\begin{array}{l}\text { Intensity } \\
\text { Pleasantness }\end{array}$ & $\begin{array}{l}-3.50 \text { to }-1.00 \\
-3.50 \text { to }-1.00\end{array}$ & .31 & .98 & $\begin{array}{l}.34 \\
.44\end{array}$ & $\begin{array}{l}.94 \\
.55\end{array}$ & $\begin{array}{l}.35 \\
.38\end{array}$ & $\begin{array}{l}.96 \\
.52\end{array}$ \\
\hline Benzaldehyde & $\begin{array}{l}\text { Intensity } \\
\text { Pleasantness }\end{array}$ & $\begin{array}{l}-3.75 \text { to }-1.00 \\
-3.75 \text { to }-2.00\end{array}$ & .30 & .97 & $\begin{array}{r}.32 \\
-.20\end{array}$ & $\begin{array}{l}.97 \\
.28\end{array}$ & $\begin{array}{r}.35 \\
-.13\end{array}$ & $\begin{array}{l}.85 \\
.10\end{array}$ \\
\hline $\begin{array}{l}\text { Benzyl } \\
\text { Acetate }\end{array}$ & $\begin{array}{l}\text { Intensity } \\
\text { Pleasantness }\end{array}$ & $\begin{array}{l}-3.75 \text { to }-1.00 \\
-3.75 \text { to }-2.75\end{array}$ & .25 & .93 & $\begin{array}{l}.22 \\
.36\end{array}$ & $\begin{array}{l}.89 \\
.65\end{array}$ & $\begin{array}{l}.25 \\
.34\end{array}$ & $\begin{array}{l}.79 \\
.40\end{array}$ \\
\hline Eugenol & $\begin{array}{l}\text { Intensity } \\
\text { Pleasantness }\end{array}$ & $\begin{array}{l}-4.00 \text { to }-1.00 \\
-4.00 \text { to }-1.00\end{array}$ & .23 & .91 & $\begin{array}{l}.23 \\
.01\end{array}$ & $\begin{array}{l}.91 \\
.01\end{array}$ & $\begin{array}{l}.30 \\
.31\end{array}$ & $\begin{array}{l}.91 \\
.73\end{array}$ \\
\hline Furfural & $\begin{array}{l}\text { In tensity } \\
\text { Pleasantness }\end{array}$ & $\begin{array}{l}-3.25 \text { to }-1.00 \\
-3.00 \text { to }-1.00\end{array}$ & .36 & .98 & $\begin{array}{r}.39 \\
-.47\end{array}$ & $\begin{array}{l}.98 \\
.96\end{array}$ & $\begin{array}{r}.38 \\
-.70\end{array}$ & $\begin{array}{l}.97 \\
.88 * *\end{array}$ \\
\hline Geraniol & $\begin{array}{l}\text { Intensity } \\
\text { Pleasantness }\end{array}$ & $\begin{array}{l}-2.50 \text { to }-1.00 \\
-2.50 \text { to }-1.00\end{array}$ & .35 & .95 & $\begin{array}{l}.31 \\
.37\end{array}$ & $\begin{array}{l}.94 \\
.01\end{array}$ & $\begin{array}{l}.34 \\
.15\end{array}$ & $\begin{array}{l}.86 \\
.22\end{array}$ \\
\hline $\begin{array}{l}\text { Methyl Ethyl } \\
\text { Ketone }\end{array}$ & $\begin{array}{l}\text { Intensity } \\
\text { Pleasantness }\end{array}$ & $\begin{array}{l}-4.00 \text { to }-1.00 \\
-2.50 \text { to }-1.00\end{array}$ & .36 & .99 & $\begin{array}{r}.37 \\
-.69\end{array}$ & $\begin{array}{l}.95 \\
.91\end{array}$ & $\begin{array}{r}.36 \\
-.81\end{array}$ & $\begin{array}{l}.97 \\
.91\end{array}$ \\
\hline $\begin{array}{l}\text { Methyl } \\
\text { Salicylate }\end{array}$ & $\begin{array}{l}\text { Intensity } \\
\text { Pleasantness }\end{array}$ & $\begin{array}{l}-4.00 \text { to }-1.00 \\
-4.00 \text { to }-1.00\end{array}$ & .21 & .84 & $\begin{array}{l}.21 \\
.30\end{array}$ & $\begin{array}{l}.87 \\
.76\end{array}$ & $\begin{array}{l}.21 \\
.23\end{array}$ & $\begin{array}{l}.82 \\
.74\end{array}$ \\
\hline $\begin{array}{l}\text { Phenyl Ethyl } \\
\text { Alcohol }\end{array}$ & $\begin{array}{l}\text { Intensity } \\
\text { Pleasantness }\end{array}$ & $\begin{array}{l}-4.00 \text { to }-1.00 \\
-4.00 \text { to }-1.00\end{array}$ & .22 & .94 & $\begin{array}{l}.22 \\
.19\end{array}$ & $\begin{array}{l}.92 \\
.46\end{array}$ & $\begin{array}{l}.32 \\
.19\end{array}$ & $\begin{array}{l}.95 \\
.74\end{array}$ \\
\hline
\end{tabular}

*Lowest concentration $=$ lowest dilution whose mean magnitude estimate differed significantly from diluent control $(t$ tests, $\cdot p<.05)$. All concentrations in log volumes.

**Based upon -2.50 to -1.00 concentrations since other concentrations assigned " 0 "s.

n.s.; SE 30 retention time, -0.46 , n.s.; vapor pressure ( $\mathrm{mm} \mathrm{Hg}$ ca. $20^{\circ} \mathrm{C}$ ), 0.35 , n.s.; dipole moment, 0.87 , p $<.01$; density (ca. $20^{\circ} \mathrm{C}$ ), -0.35 , n.s.

\section{DISCUSSION}

The results of the present experiment suggest that (a) the pleasantness of olfactory stimuli varies with

Table 2

Percentage of Observers Assigning the Majority of the Stimulus Concentrations Pleasant (t), Unpleasant (-), or Neutral (0) Values

\begin{tabular}{|c|c|c|c|c|c|}
\hline \multirow[b]{2}{*}{ Odorant } & \multirow{2}{*}{$\begin{array}{c}\text { Sample } \\
\text { Size }\end{array}$} & \multicolumn{3}{|c|}{$\begin{array}{c}\text { Percentage } \\
\text { Assigning }\end{array}$} & \multirow[b]{2}{*}{ Chi Square } \\
\hline & & + & - & 0 & \\
\hline iso-Amyl Ace tate & 20 & 65 & 35 & $\mathbf{0}$ & $1.80 \dagger \dagger$ \\
\hline Anethole & 35 & 66 & 17 & $14 \dagger$ & $18.78^{* *}$ \\
\hline Benzaldehyde & 36 & 53 & 44 & 3 & $15.50^{* *}$ \\
\hline Benzyl Acetate & 36 & 54 & 38 & $3 \dagger$ & $16.18^{* *}$ \\
\hline Eugenol & 39 & 67 & 18 & $10 \dagger$ & $23.09^{*}$ \\
\hline Furfural & 37 & 25 & 75 & 0 & $9.00 \dagger \dagger * *$ \\
\hline Geraniol & 37 & 68 & 27 & $0 \dagger$ & $6.42+\dagger$ \\
\hline Methyl Ethyl Ketone & 32 & 41 & 34 & 25 & 1.19 \\
\hline Methyl Salicylate & 17 & 71 & 12 & $12 \dagger$ & $12.51 \dagger \dagger * *$ \\
\hline Phenyl Ethyl Alcohol & 35 & 72 & 17 & 11 & $23.02 * *$ \\
\hline
\end{tabular}

tThe sum of the,,+- and 0 percentages does not sum to 100 in these cases since the data of a few observers who reported equal numbers of,+- , or 0 responses were omitted.

tfBased only upon - and + categories, as the null frequency in the 0 category invalidates the use of the chi square statistic (Siegel, 1956).

$\begin{aligned} * p & <.02 \\ * p & <.001\end{aligned}$ their physical concentration, (b) pleasantness and intensity are closely related psychological dimensions for some odorants, (c) power functions describe quite well, in most cases, the relationship of physical concentration to perceived intensity, but not to perceived pleasantness, and (d) large differences between observers exist in regard to the assessment of odorant hedonicity. Although it has been previously noted that the hedonicity of odors varies considerably from individual to individual (e.g., Young, 1923; Kniep, Morgan, \& Young, 1931), little attention has been paid directly to these differences or to the importance of odorant concentration in their attenuation or diminution. It is possible that the thresholds of individuals who consistently rate some odors pleasant are higher than those of subjects who rate them unpleasant, although substantiation of this point is needed. Since pleasantness appears to be a major dimension of the odorant classification schemes of many observers (Harper, Smith, \& Land, 1968; Yoshida, 1964), attempts to multidimensionally scale odorants without taking into account concentration permutations may lead to misleading and tenuous odor spaces (e.g., Schiffman, 1974). This is particularly true for studies using odorants which have concentration-dependent trigeminal stimulative properties (e.g., acetone, ammonia, furfural, methyl ethyl ketone).

Since varying numbers of individuals were used in the determination of the exponents for the compounds of this study, the present results may be viewed, to 
some extent, as having come from 10 independent experiments. It should be noted that the intensity exponents of the present study correlated only moderately with those reported by Berglund et al. (1971). who had the same observers make all judgments against a reference odorant $(100 \%$ acetone) ( $r=0.67$ for geometric means). Whether the addition of a comparison "anchoring" stimulus would have markedly influenced the magnitude of the exponents determined in the present study is not known. The sizes of the intensity exponents of this study fall into the general range of exponents reported by others for similar olfactory stimuli (e.g., Engen, Note 1), although their overall magnitude was higher than those reported by Berglund et al. (1971). Differences between observers, odorant presentation procedures, ranges of concentrations examined, and diluents may account for these differences.

The finding of a significant correlation between water solubility and the magnitude of the intensity exponent is in accord with previous results of Cain (1969). However, significant correlations were also found in the present study between the intensity exponent values and molecular weight and dipole moment, suggesting that complex interrelations may exist between physicochemical and psychophysical parameters. Since many physicochemical indices are interrelated (e.g., water solubility and dipole moment are typically related), it is not known which factor or combination of factors are of contributory importance to this phenomenon. It should be pointed out that the correlation found in the present study between the intensity exponents and solubility factors may represent, to some extent, differential interactions of the solutes with the highly polar solvent, propylene glycol. Thus, departure from ideal gas laws may be unequal for the various compounds across the concentrations used in this study. The fact that intensity exponents for olfactory data based upon air dilution concentrations are typically larger than intensity exponents based upon liquid dilution (e.g., Cain, 1969; Moskowitz, personal communication) suggests that air dilution studies may be necessary in order to establish formulae for correcting for such solute-solvent interactions.

\section{REFERENCE NOTE}

1. Engen, T. Direct scaling of odor intensity. Report from the Psychological Laboratories, University of Stockholm, 1961, No. 106.

\section{REFERENCES}

Berglund, B., Berglund, U., Ekman, G., \& Engen, T. Individual psychophysical functions for 28 odorants. Perception \& Psychophysics, 1971, 9, 379-384.

CaIN, W. S. Odor intensity: Differences in the exponent of the psychophysical function. Perception \& Psychophysics. 1969, 6, 349-354.

DoTY, R. L. Intranasal trigeminal detection of chemical vapors by humans. Physiology and Behavior, 1975, in press.

Engen, T., \& Lindström, C. O. Psychophysical scales of the odor intensity of amyl acetate. Scandinavian Journal of Psychology, 1963, 4, 23-28.

Harper, R., Smith, E. C., \& LaNd, D. G. Odour description and odour classification. New York: American Elsevier, 1968.

Henion, K. E. Odor pleasantness and intensity: A single dimension. Journal of Experimental Psychology, 1971, 90. 275-279.

Jones, F. N. Subjective scales of intensity for the three odors. American Journal of Psychology, 1958. 71, 423-425.

KnieP, E. H., Morgan, W. L., \& Young, P. T. Studies in affective psychology. XI. Individual differences in affective reaction to odors. American Journal of Psychology, 1931, 43, 406-421.

MoncriefF, R. W. Odour preferences. London: Leonard Hill, 1966.

Moskowitz, H. R., Dravnieks, A., \& Gerbers, C. Odor intensity and pleasantness of butanol. Journal of Experimental Psychology, 1974, 103, 216-223.

ReEse, T.S., \& Stevens, S. S. Subjective intensity of coffee odor. American Journal of Psychology, 1960, 73, 424-428.

SAx, N. I. Dangerous properties of industrial materials. New York: Reynold, 1966.

Schiffman, S. S. Physicochemical correlates of olfactory quality. Science, 1974, 185, 112-117.

SIEGEL, S. Nonparametric statistics for the behavioral sciences. New York: McGraw-Hill, 1956.

TORGERSON, W. S. Theory and methods of scaling. New York: Wiley, 1958.

Yoshida, M. Studies of psychometric classification of odors. Japanese Psychological Research, 1964, 6, 145-154.

Young, P. T. Constancy of affective judgment to odors. Journal of Experimental Psychology, 1923, 6, 182-191.

(Received for publication A pril 1974; revision received February 11, 1975.) 